\title{
Correspondence
}

Controlled trial of continuous positive airway pressure given by face mask for hyaline membrane disease-killer Pascals

Sir,

The problems of conversion to SI units are amply illustrated in the interesting article by Allen and coworkers in the May Archives, $(1977,52,373)$. 1 wish to point out an error, both in the text and in Table 3 , in which pressures recorded in SI units for CPAP and ventilator therapy are wrong by a factor of 10 , e.g. in Table 3 peak airway pressure in the early-intervention group should read 2.0 and not $0.20 \mathrm{kPa}$, the latter being equivalent to a pressure of only $2 \mathrm{~cm}$ of water. Should ventilator settings as shown in Table 3 be used, survival statistics would truly be decimated!

In comparing the composition of the early- and lateintervention groups, the authors rightly comment that the latter group contained the smallest infant, presumably that of 24 weeks' gestation, and 3 infants with coagulation disorders. There are other differences, however, which though not significant when taken in isolation, may have militated against survival in this late-intervention group: the mean age of entry into the trial was lower in the lateintervention group, suggesting perhaps that the condition was more severe. Secondly, the late-intervention group contained only 1 girl, compared to 3 of the 12 babies in the early-intervention group. Since the prognosis in hyaline membrane disease, as in many other neonatal disorders, tends to be worse in boys, this may also have influenced the results in the late-intervention group.

There are no details of the ages of the infants when assisted ventilation was begun. Presumably CPAP was started at the time of entry to the trial in the earlyintervention group. How much later was assisted ventilation started in the second group? Was the age at intervention significantly different in the two groups?

C. HEWITT

Paediatric Assessment Unit, City Hospital, Hucknall Road, Nottingham NG5 IPD.

Professor Reynolds replies as follows:

We thank Dr. Hewitt for pointing out the error in the conversion of $\mathrm{cmH}_{2} \mathrm{O}$ to $\mathrm{kPa}$ in our paper with the above title. We must, however, plead mitigating circumstances as the paper was submitted with values in $\mathrm{cmH}_{2} \mathrm{O}$, and the conversions were done by the editorial office of the Archives. We should have noticed the mistake when proof-reading the paper, but did not.

With regard to Dr Hewitt's other comments, we agree that there are factors which may have adversely affected survival in the late-intervention group. As he says, we discussed some of these. We are not claiming a difference in survival between the two groups.

The age at which CPAP was started in the earlyintervention group was, as Dr. Hewitt surmised, at entry to the trial (mean $15 \cdot 8 \mathrm{~h}$ ). The age at intervention with CPAP or mechanical ventilation in the late-intervention group was not significantly greater (mean $18.0 \mathrm{~h}$ ). We do not think that these matters affect the stated conclusions of our paper, that early-intervention with CPAP reduces the need for high inspired oxygen concentrations and, probably more importantly, allows infants who go on to require mechanical ventilation to be ventilated at lower pressures.

E. O. R. REYNOLDS Paediatric Department, University College Hospital, Huntley Street, London WC1E 6AU.

We apologize for the errors in the conversions to SI units in Professor Reynolds' paper, and an Erratum appears elsewhere in this issue. Eds.

\section{Comparison of systems of estimating skeletal age}

Sir,

Bone age estimations are of much value in clinical paediatrics, but the standards used must be appropriate for the population of children under consideration. Because of speed and convenience the Atlas of Pyle et al. (1971) is the most commonly used standard by British radiologists, but these standards were based on upper-class American children and are not comparable to the average British population, sometimes giving an estimate that differs by as much as 2 years. The Pyle technique of assessment is approximate, depending on a series of $x$-rays of hands attributed to normal average children of particular ages. Most clinicians will interpret bone ages from these $x$-ray standards primarily on the features of the carpal centres, which may not correlate well with long bone centres.

The standards of Tanner et al. (1975) were developed from middle-class British children. Their method is time-consuming and laborious but more precise, depending on an overall assessment of maturity of 20 different centres involving the long bones and round bones of the wrist and hand.

It seemed of interest to compare the ratings of these two techniques by estimating the bone ages of the 26 'standard hands' displayed in the Atlas of Pyle et al. in the 


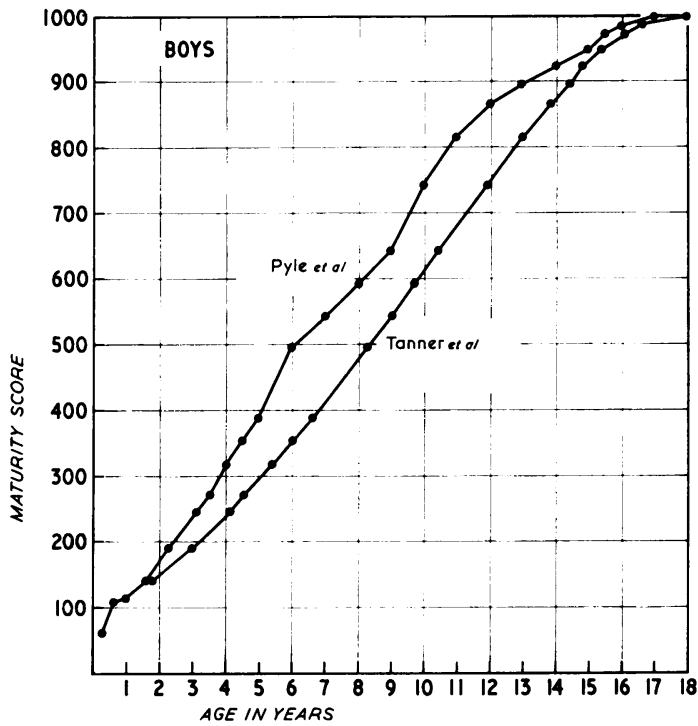

(a)

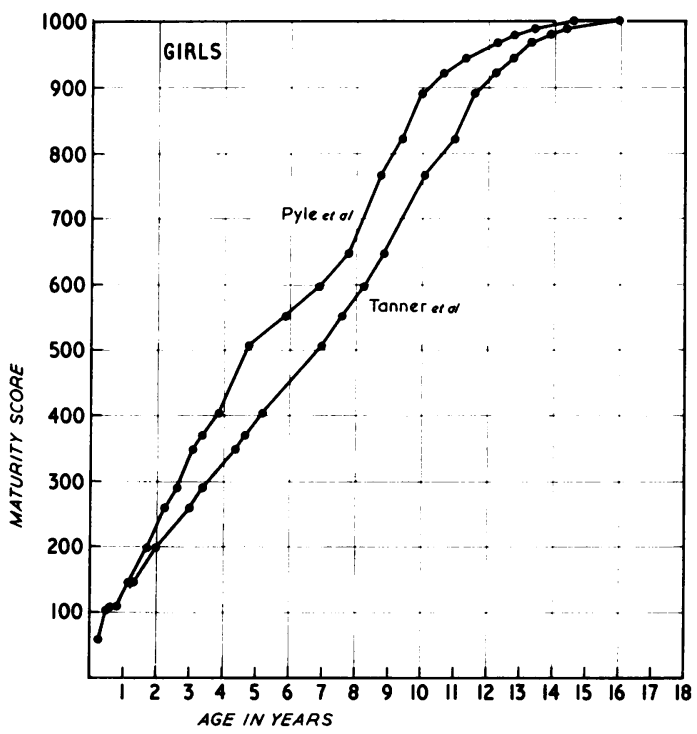

(a)

Fig. Comparison of skeletal maturity assessments by two different systems. (a) Boys, (b) girls.

terms of the Tanner system (TW2). The results are shown in the Fig. for boys and girls, and shows the significant differences which may be obtained, the American standards always being advanced compared with the British.

Clearly, the technique chosen in estimating bone age can greatly alter its value in diagnosis. It is not suggested that the figures shown should be used as a short cut to the more accurate assessment by the method of Tanner $e t$ al., for this, as already indicated, takes into consideration overall variations in the rate of development of individual bones and so avoids the approximations of the system of Pyle et al.

J. M. H. BUCKLER, Department of Paediatrics and Child Health, University of Leeds, 27 Blundell Street, Leeds LSI 3ET.

\section{References}

Pyle, S. I., Waterhouse, A. M., and Greulich, W. W. (1971) A Radiographic Standard of Reference for the Growing Hand and Wrist. Press of Case Western Reserve University, Chicago. (Distributed by Yearbook Medical Publishers, Chicago.)

Tanner, J. M., Whitehouse, R. H., and Marshall, W. A. (1975). Assessment of Skeletal Maturity and Prediction of Adult Height (TW2 Method). Academic Press, London.

\section{Folic acid levels in erythroblastotic infants}

\section{Sir,}

May I clarify the reference to our studies of erythroblastotic infants in one of the recent excellent papers by Drs. Gandy and Jacobson? It is stated that we found low whole-blood folate levels in some erythroblastotic infants and that 2 who were severely anaemic showed a haematological response to daily intramuscular folic acid of 0.12-0.48 mg (Gandy and Jacobson, 1977). It might be of interest to give haematological details of the 2 erythroblastotic infants who showed a rise in reticulocytes and haemoglobin on intramuscular folic acid (Strelling et al., 1966; Strelling, 1973).

The findings were as follows.

(1) 11 infants were examined who were moderately or severely affected by $R h$ isoimmunization and required between 1 and 6 exchange transfusions. Between the 3rd and 10th weeks their mean lowest haemoglobin was $7 \cdot 8 \mathrm{~g} / \mathrm{dl}$ (range 5.9-9.5 g/dl) and the mean lowest red cell folate in 9 infants not receiving folic acid' was $170 \mu \mathrm{g} / \mathrm{l}$ (range 57-333 $\mu \mathrm{g} / \mathrm{l}$ ). As we reported, buffy coat smears of peripheral blood showed no signs of folate deficiency, but the red cell folate in 4 infants was below the range found in healthy controls of this age (range 110-655 $\mu \mathrm{g} / 1$, mean $261 \mu \mathrm{g} / \mathrm{l}$ ).

(2) The 2 erythroblastotic infants who showed a haematological response after folic acid were treated as follows. (i) Infant J. H. Birthweight $2.36 \mathrm{~kg}$, gestation 34 weeks. One exchange transfusion. On day $40 \mathrm{Hb}$ was $6.7 \mathrm{~g} / \mathrm{dl}$, reticulocytes $1 \%$ and red cell folate $100 \mu \mathrm{g} / 1$. Intramuscular folic acid $5 \mathrm{mg}$ daily was given for 3 days and after a week for a further 5 days. On day 8 the reticulocytes had risen to $14 \%$, and after an initial fall to $5.9 \mathrm{~g} / \mathrm{dl} \mathrm{Hb}$ rose to $8.2 \mathrm{~g} / \mathrm{dl}$ on day 15 and to $10.8 \mathrm{~g} / \mathrm{dl}$ on day 28. (ii) Infant $\mathrm{S}$. W. Birthweight $2 \cdot 3 \mathrm{~kg}$, gestation 